\title{
Understanding wider environmental influences on mentoring: Towards an ecological model of mentoring in academic medicine
}

\author{
Dario Sambunjak ${ }^{*}$ \\ Department of Sociology, Catholic \\ University of Croatia
}

\footnotetext{
${ }^{*}$ Corresponding author: dario.sambunjak@unicath.hr Tel.: + 38513706642 Fax.: + 38513706601
}

Received: 5 February 2015

Accepted: 8 March 2015

Key words: Mentors - Education Medical • Models • Educational

\begin{abstract}
Mentoring is a complex developmental relationship that contributes to individual growth and career advancement in different areas of human activity, including academic medicine. This article describes a broader environmental milieux in which mentoring occurs and considers the ways in which the environmental factors may affect the process and outcomes of mentoring. An ecological model of mentoring is proposed that takes into account various factors broadly operating at three contextual levels. The first is societal or "macro" level, which implies cultural, economic, and political factors. The second is institutional or "meso" level, consisting of a) system-related factors such as field and discipline characteristics, and government policies, and b) organization-related factors such as mentoring climate, reward structure, and work design. The third contextual level relates to intrapersonal and interpersonal characteristics of mentor-mentee dyads. If mentoring dyad is viewed as the focal point, societal and institutional levels may be labeled as "external", and personal level as "internal". The conceptual diversity and methodological challenges in the study of mentoring need to be acknowledged, but should not be an excuse to leave the external contextual elements out of the researchers' horizon, as they inevitably shape and modify the mentoring relationships. Conclusion. Model presented in this article offers a holistic view of mentoring in academic medicine that may help one comprehend and appreciate the complexity of influences on mentoring, and inform the future research agenda on this important topic.
\end{abstract}

\section{Introduction}

Mentoring is a complex developmental relationship that contributes to individual growth and career advancement (1). This social construct has been extensively investigated in different contexts and settings, including social work, education, business, medicine and health care (2-4). In academic medicine, mentoring was recognized to have an important influence on personal development, career choice and navigation, and research productivity (5).

Most of the mentoring research was focused on the intrapersonal and interpersonal factors affecting dyadic relationships. On the intrapersonal level, mentor-related variables such as mentoring schemas (6), mentoring style (7), motivation to mentor (8), and mentor's experience as protégé (1, 
9) were suggested to have an impact on the development and quality of relationships. Mentee-related variables can be broadly categorized in resources (10) and needs (11). On the interpersonal level, several factors and domains have been suggested to influence the mentoring relationships: perceived similarity (12), frequency of interaction (12), relational competence (13), congruency of expectations (6), and cost-benefit assessment (14).

Mentoring relationships, however, do not occur isolated from their environment. In a systematic review of mentoring in academic medicine, authors concluded that "mentoring is inextricably situated in a social context and shaped by the institutional culture and climate" (15). It follows that an integrative model of mentoring, which I will call the ecological model, has to include three contextual levels - societal (or "macro"); institutional (or "meso"), which can be further divided into system- and organization-level; and personal (or "micro"), which includes intrapersonal and interpersonal variables (Figure 1).

If mentoring dyad is viewed as the focal point, societal and institutional levels may be labeled as "external", and personal level as "internal". The latter is empirically better explored than former and several theoretical models of what I call personal or internal level have been proposed by the researchers in medical setting $(16,17)$. Institutional and societal levels, on the other hand, still need a theoretical explication to inform and underpin further research efforts.

The term ecological mentoring has previously been described and used to denote an integrative, holistic or synthetic approach to mentoring, which takes into account elements that may operate at different levels $(18,19)$. Throughout this paper I will adopt this term and use it to conceptualize a model in which complex interplay of various factors operating at different levels may all affect mentorship. As for the definition of mentoring, I will consider it as a face-to-

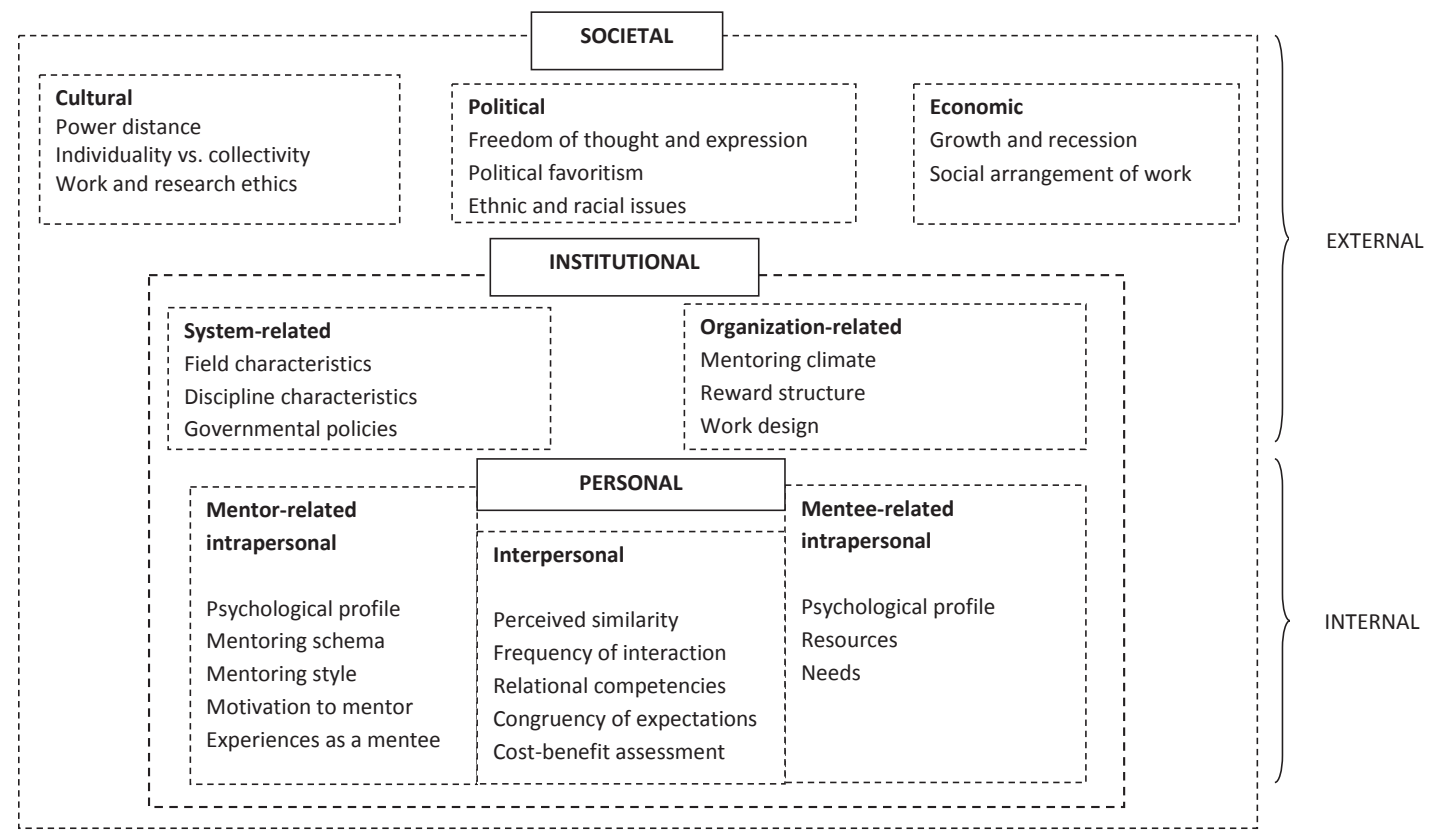

Figure 1 Integrative model of contextual levels and the related factors or domains that shape mentoring relationships. Dashed lines signify the "porousness" of the between-level borders: to some degree, levels overlap and affect each other. In a globalized and multicultural world, borders of the societal context are also "porous". 
face, dyadic, and hierarchical relationship whose primary purpose is personal growth and professional development of the mentee, but whose beneficial impact extends to the mentor and a broader environment in which the relationship is embedded. In this relationship, which may be formally or informally initiated, mentors provide career and psychosocial functions to support the mentee. Mentoring implies a high level of commitment and continues over a longer period of time. This comprehensive definition is necessary to achieve conceptual clarity and avoid the confusion of mentoring with other types of developmental relationships, such as supervising or coaching (20).

The aim of this article is to describe a broader environmental milieux in which mentoring occurs and discuss the ways in which these environmental factors may affect the process and outcomes of mentoring.

\section{INSTITUTIONAL CONTEXT}

In this model, the term "institutional" refers to the system-related factors such as fieldand discipline-characteristics and governmental policies, as well as the organizationrelated factors such as mentoring climate, reward system and work design in a particular institution (Figure 1).

\section{System-related factors}

\section{Field characteristics}

Academic medicine, considered here as a field within medicine, is a part of a wider scholarly environment, in which mentoring traditionally had a significant position within the apprenticeship model of graduate and professional education (21). Higher education in general consists of teaching and research activities, but academic medicine has an additional responsibility of providing health care to patients and populations. These three areas of activity are increasingly difficult to balance in a single career. Clini- cal care is burdened by demographic trend toward aging that results in increased severity and complexity of illnesses, while at the same time service expectations from patients are rising. Research has become highly competitive and resource-demanding. Educational reforms such as Bologna process in the European Union create additional burden of teaching, yet teaching activities are usually less valued in career assessment than research or clinical performance. The cumulative effect of these trends can have a detrimental impact on job satisfaction and diminish attractiveness of academic careers. Successful mentoring can provide psychosocial support, role modeling and career advice needed to overcome the challenges of working in academic medicine, yet it is exactly these challenges that are reducing the number and availability of mentors.

\section{Discipline characteristics}

Specific features of disciplines within academic medicine, such as recency, propulsiveness or interdisciplinarity, can produce different conditions that are more or less conducive for mentoring relationships. More recently developed disciplines, such as bioinformatics or conflict medicine, may be less likely to have a strong pool of potential mentors, as there was not much time for the development of many senior researchers and practitioners. Propulsive disciplines such as genetics and immunology may attract more resources than others, thus producing more opportunities for recruitment of new mentees, which in turn provides senior academics with more chances to try out and hone their mentoring skills. More interdisciplinary research areas and those that are dealing with more complex problems may require input from multiple mentors. Mentees in such disciplines may be more inclined to look for support from various sources, thus expanding their mentoring networks. 
Differences in medical specialties may modulate the delivery of mentoring functions. In surgical disciplines the emphasis in mentoring may be on coaching to increase practical skills in performing operations. On the other hand, mentees in psychiatry may need more counseling, e.g. debriefing after dealing with emotionally demanding patients. Mentors in research-oriented disciplines such as genetics or pharmacology will generally be more able to provide a solid training in research activities, whereas mentors in clinically-oriented disciplines such as internal medicine, pediatrics or gynecology would be more helpful in fostering mentees' clinical performance and professional socialization.

General practice or family medicine builds the foundation of any healthcare system, yet its position as an academic discipline is sometimes challenged or poorly recognized. General practitioners work in the conditions of increased accountability with decreased professional autonomy, which contributes to demoralization and stress in the profession $(16,22,23)$. Excessive workload of general practitioners in academic medicine may reduce their availability as mentors. General practices are usually operating in relative isolation from each other and even from other members of the health system, which limits the opportunities for academic interaction and initiation of mentoring relationships.

\section{Government policies}

Official government policies on healthcare, science and higher education constitute the most general formal framework in which mentoring relationships grow. Some policies are conducive for such growth - for example, when governments provide salaries for a certain number of research fellows who are adjoined to the ministry-sponsored research projects of senior members of aca- demic community (24). This support facilitates recruitment of young scientists and their early connection with more experienced researchers who can potentially offer them a full range of mentoring functions. In reality, however, this potential is not always realized. Government-supported research projects may not be sufficiently discriminative and may lack a functioning system of monitoring and evaluation of performance (25). In such circumstances, mentoring relationships can be affected by a lack of political will or mechanisms to ensure full implementation of well-intended official policies.

\section{Organization-related factors}

\section{Organizational culture}

The effect of organizational culture is possibly the best explored and documented external-level element of the ecological model of mentoring. Department climate can influence values and attitudes of organizational members, often through the actions and role-modeling of mentors who assist their mentees as they are socialized into a community's practices. One manifestation of a developmental climate in institutions of academic medicine is the existence of formal mentoring programs, which represent a conscious use of faculty experience to develop students and early-career physicians. Formal mentoring programs have been initiated and reported in different medical institutions and settings, although their effectiveness has not been convincingly established due to descriptive nature of most of the reports (26).

Some research has indicated that formal mentoring is less effective than informal (27). The latter, of course, cannot be arranged or assigned. However, institutions may facilitate spontaneous development of mentoring by providing the structure, processes and expectations for such relation- 
ships to occur. For example, they can offer workshops for students and junior faculty to help them build up the skills and competencies necessary to develop effective informal mentoring relationships. Other interventions may be directed towards the design of work.

\section{Work design}

In her seminal work on mentoring in business organizations, Kram suggested that the design of work, including its structure and processes, can facilitate or interfere with building relationships that provide mentoring functions (1). Although collaborative and team work is a common feature of academic medicine, both medical profession and academic community are characterized by hierarchical structures which can deter newcomers from attempts to establish more personal contact with those in senior positions. To overcome this obstacle, academic institutions can encourage interactions and communication between senior and junior faculty, and students, by establishing regular semi-formal meetings and journal clubs, or trying innovative approaches such as "speed-mentoring" events (28).

Development of long-term mentoring relationships between faculty and undergraduate medical students is often hindered by a disconnection between preclinical and clinical years of study, and continual course rotation. These challenges could be overcome by promoting students' longitudinal relationships with clinicians through continuity clinics and research projects (29) or by combining peer-to-peer mentoring with physician-to-student mentoring (30).

Work design can vary depending on the type of academic institution. Study conducted in a transition country has shown that the type of institution was associated with the success of research trainees: research institutes had a highest rate of mentees who completed their fellowships with a $\mathrm{PhD}$ degree; this rate was lower at the schools of medicine, and even lower at the university clinics (31). This can likely be explained by the primary mission of each type of institution, namely research, teaching, or clinical care.

\section{Reward structure}

Institutional expectations are reflected in the reward structure and criteria for promotion. In academic institutions, research productivity is often valued and rewarded more than educational excellence (32). This may be due to the fact that the number of published articles and obtained grants is more convenient to track than the quality of teaching. A complex developmental relationship such as mentoring is even more difficult to quantify than teaching. To limit this bias against educational activities and improve their mentoring climate, some institutions have established awards for outstanding mentorship (33). There are, however, some challenges in deciding about the best mentorship in an institution. Only a few instruments have been developed to assess the quality of mentoring and that mostly for research purposes (34). Someone's mentoring quality cannot be established by a popular vote, as much effective mentoring is informal, one-to-one interaction that occurs out of the horizon of most other institutional members. Furthermore, best mentors may not necessarily have more than one or a few mentees at any given time, so they cannot attract many votes. The rate of successfully mentored graduate students may be a longterm outcome more appropriate to assess the quality of academic mentoring, but this outcome fails to account for mentoring provided to undergraduate students and junior faculty.

Institutions may decide to openly reward participation in formal mentoring pro- 
grams. Such a decision gives a clear signal about organizational expectations, which can result in some senior members volunteering for the mentoring role half-heartedly, only to meet the expectations. Less overt approaches may prove more beneficial, for example when department heads take the lead in accepting and working with mentees, thus championing formal mentoring programs.

\section{SOCIETAL CONTEXT}

All social interactions, including mentoring and other developmental relationships, are situated in a context shaped by cultural, economic and political factors.

\section{Cultural factors}

Culture comprises the ideas, beliefs, and knowledge that characterize a particular group of people. Cultural identity is most commonly conceptualized as nationality or ethnicity, but Chao and Moon pointed out that multiple cultural identities may arise from demographic, geographic, and associative features (35). Mentoring research has mostly addressed the demographic features such as gender and race as possible modifiers (13), often in relation to perceived similarity between the two actors in the relationship.

In his insightful discussion of the wider international perspective on mentoring, Clutterbuck emphasized two cultural dimensions as particularly relevant - power distance and individuality (7). The power distance or stance towards authority affects the mentees' willingness to challenge what they are told. For example, a suggestion that mentees should be selective in accepting advice from mentor (36) is typical for a low power distance culture. Power distance may also influence mentees' agility in seeking informal mentors. Consequently, formal mentoring programs may be especially beneficial in cultures with a high power distance. This cultural dimension may also make it easy or difficult for either mentor or mentee to express emotions and permit vulnerability, thus affecting the provision of psychosocial mentoring functions. Power distance is related to performance orientation, a cultural variable defined as the degree to which an organization or society encourages and rewards group members for performance improvement and excellence. In an early example of a study empirically exploring cultural influences on mentoring, Gentry and colleagues used a multinational sample of practicing managers to prove their hypothesis that performance orientation is a significant cross-level moderator of the relationship between career-related mentoring and performance (37). A more recent study in the organizational setting showed that power distance weakens the impact of career and psychosocial mentoring on the motivation of subordinates (38).

Individuality is the other dimension suggested by Clutterbuck as important for understanding mentoring in different cultural contexts (7). In cultures that emphasize individuality, rather than collectivity, each individual is considered chiefly responsible for developing and maintaining their own developmental relationships or - in the words of participants of a Canadian study - taking "the driver's seat" (39). Highly individualistic cultures may inhibit mentors' responsiveness to mentees' needs and devalue efforts put in the development of others.

Work ethics is another important cultural factor that may influence the development and nature of mentoring relationships in academic medicine. Through their rolemodeling, mentors perpetuate and support certain work ethics, which may or may not be compatible with the standards and values of academic medicine internationally. An important concept related to the issue of work ethics is research integrity. Biomedicine 
is a research-intensive field of science and much of this research is carried out at the academic institutions. High research productivity in biomedicine can be explained by a considerable funding of medicine- and health-related research, but also by a strong pressure to "publish or perish". Such a pressure may push some members of academic community towards scientific misconduct, especially if fraudulent behavior is widespread and tacitly tolerated in a society. Social norms such as the rule of law, corruption and democratic accountability differ across cultural regions of the world (40). These social norms may reflect in the inclination of mentors in academic medicine to commit or tolerate scientific misconduct. Both through their role-modeling and direct communication, mentors provide information about the ethical behaviors, moral obligations, and codes or regulations to which their mentees are expected to adhere within the academic community.

\section{Economic factors}

Economy may shape the nature and role of mentoring in human society in profound, if not immediately obvious ways. Savickas suggested that mentoring came into focus as "a societal response to the reorganization of the work world occasioned by the global economy" (41). Work of the $21^{\text {st }}$ century is characterized by the fragmentation and lack of security, with assignments and projects replacing permanent jobs and careers. Such a social arrangement of work requires constant negotiation of transitions, life-long learning, and continuous progression of developmental relationships, including mentoring. It is therefore not surprising that the concept of mentoring networks or mentoring constellations rapidly developed only during the last 15 years $(42,43)$.

In many respects, today's academic medicine bears the marks of contemporary so- cial arrangement of work. This is visible, for example, in temporary nature of research fellowships and postdoctoral positions, requirement of mobility, need to juggle the "triple threat" of an academic career, and permanent evaluation of performance and output. Such an arrangement of work may increase stress, tensions (including problems in work-family balance), job insecurity, and role ambiguity among physicians in academic medicine, producing a need for additional psychosocial and career support by mentors. The same socio-economic pressures, however, are also acting on the side of mentors, limiting their availability and capacity to provide the needed support. Anxiety over keeping jobs and obtaining research grants drains the mentors' emotional energy necessary for building positive developmental relationships. In the business context, Allen and colleagues found that mentors are reluctant to invest their time and energy in developing mentoring relationships in a turbulent job environment where job security is an issue (9). In the context of academic medicine, it has been observed that economic crisis and job availability affect career choices of medical students (44). It is conceivable that concerns about job insecurity and wage reduction also have an impact on the willingness of senior faculty and physicians to commit themselves to mentoring relationships.

\section{Political factors}

Political factors refer to the official political system in a country or to the more or less unofficial "politics" and policies in academic institutions. In communist regimes of the second half of the $20^{\text {th }}$ century, freedom of thought and expression was relatively suppressed and the single-party political system prevented the development of pluralistic and democratic societies. Transition countries have changed their political systems, 
but the underlying values and habits of their citizens, including many of the senior academics, are shaped by the experiences of living under totalitarian political regimes. Due to these formative experiences, some mentors in transition countries never learned to speak truth to the power or even to participate in a truly democratic discourse. Consequently, they are ill-equipped to help their junior colleagues become "thoughtful, questioning professionals in regard to the society around them", which is an important responsibility of mentors in academic medicine (45). It must be emphasized that even in countries with a long-time democratic history, there is an important role of mentors in enabling younger generations of academic physicians to critically address the present position of medical profession at the crux of power, knowledge and technology (45).

In totalitarian political systems, eligibility based on political or ethnic affiliation was a common prerequisite for upward mobility in many state institutions, including academic ones. Political constraints inevitably affected all spheres of social life, including mentoring relationships, and made a fertile soil for the growth of political favoritism. With the change of political system from totalitarism to democracy, some progress towards meritocracy has been achieved, but the role of favoritism is far from gone. The affiliation to a political party, especially if it is the ruling one, may be of help, but even more important is the affiliation (or "connections") to an informal "party" or "club" that controls the key institutional factors, such as access to funding or promotion (46). Thus, having a mentor from within the ruling "party" may facilitate career progression on the academic ladder, whereas choosing a mentor that is in the opposition to the ruling "party" may result in career difficulties or even drop-out from academic medicine.

In some countries, social and political developments throughout the history have led to certain racial and ethnic minority groups being underrepresented in the academy, relative to the overall population. There is an increasing number of formal mentoring programs developed in academic institutions to address unique challenges faced by underrepresented minority faculty (47). There is some evidence that mentoring and faculty development programs for minority faculty can increase retention, academic productivity and promotion rates for this group $(47,48)$.

\section{IMPLICATIONS FOR RESEARCH}

Quantitative research of mentoring in academic medicine has mostly dealt with prevalence and outcomes, and was found to be limited by cross-sectional design of the majority of studies (5). Mentoring was less frequently explored by qualitative research methodologies, which primarily addressed the personal contextual level of mentoring relationships (15). Organizational influences were mostly described in reports of formal mentoring programs, which were found to be poorly evaluated (26). A relatively underdeveloped research base in academic medicine can partly be explained by the methodological and conceptual challenges in studying complex developmental relationships such as mentoring $(20,34)$. The challenge of complexity becomes even greater when system- or societal-level influences on mentoring are taken into account.

The conceptual diversity and methodological challenges need to be acknowledged, but should not be an excuse to leave the external contextual elements out of the researchers' horizon, as they inevitably shape and modify the mentoring relationships. Failing to recognize the role of external context may result in a biased interpretation of the literature. For example, a wealth of studies and scholarly articles on mentoring, produced across academic disciplines and fields, may easily create a perception of 
mentoring as a well-explored and developed construct. However, most of the existing literature originates from the western developed countries $(3,5,15)$. Such geographic homogeneity or asymmetry may result in a thorough, but one-sided understanding of mentoring. Dougherty and Dreher point out that "programmatic research is needed to better understand whether the association between mentoring and career outcomes most often studied within the context of U.S. culture - will generalize to national cultures that differ from the United States" (34).

To bring such "programmatic research" to reality, academic medicine could make use of its well-established international research networks and collaborations to engage academic institutions across countries in multi-center studies of mentoring. Such studies should be carefully designed to control for various contextual variables. Theoretical lens and validated instruments should be borrowed from other academic fields such as sociology, anthropology, economics and political sciences. Use of interdisciplinary approach to study of mentoring in academic medicine will enhance our ability to elucidate and better understand this important developmental relationship.

\section{Conclusion}

Mentoring is a desirable and beneficial, albeit demanding and sometimes even challenging relationship for people working in academic medicine. It is not only in their best interest, but also in the interest of their institutions and broader communities to better understand the mentoring dynamics and processes. In contemporary academic world, issues of quality in education and research have gained a prominence and raised attention to various factors affecting the quality. Mentoring is a recognized tool for improving the quality of academic medicine. However, proper understanding of such an important and complex developmental relationship cannot be achieved without looking beyond the persons directly involved in it. As the influence of academic medicine expands in a wide range of societal contexts, so does the society have an inevitable impact on the conditions and relationships within the academic medicine. Model presented in this article offers a holistic view of mentoring that may help one comprehend and appreciate the complexity of influences on mentoring, and inform the future research agenda on this topic.

\section{What is already known on this topic}

- Mentoring is a developmental relationship that has been studied extensively in different contexts and settings, including academic medicine. The previous research has mostly focused on intrapersonal (e.g. characteristics of mentor or mentee) and interpersonal factors (e.g. $d y$ namics of mentor-mentee relationship) that influence mentoring. There were very few attempts to explore external contextual factors affecting mentoring relationship, possibly due to a lack of theoretical explication to inform and underpin such research.

What this study adds

- This article provides a comprehensive conceptual framework for future research by explicating institutional and societal context of mentoring in academic medicine. An ecological model of mentoring is proposed that takes into account relevant factors on micro-, mesoand macro level.

Conflict of interest: The author declares that he has no conflict of interest.

\section{References}

1. Kram KE. Mentoring at work: Developmental relationships in organizational life. Glenview, IL: Scott Foresman; 1985.

2. Allen TD, Eby LT, editors. The Blackwell handbook of mentoring: a multiple perspectives approach. Malden, MA: Blackwell Publishing; 2007.

3. Kashiwagi DT, Varkey P, Cook DA. Mentoring programs for physicians in academic medicine: a systematic review. Acad Med. 2013;88:1029-37.

4. Dorsey LE, Baker CM. Mentoring undergraduate nursing students: assessing the state of the science. Nurse Educ. 2004;29:260-5. 
5. Sambunjak D, Straus SE, Marusic A. Mentoring in academic medicine: a systematic review. JAMA. 2006;296:1103-15.

6. Ragins BR, Verbos AK. Positive relationships in action: Relational mentoring and mentoring schemas in the workplace. In: Dutton JE, Ragins BR, editors. Exploring positive relationships at work: Building a theoretical and research foundation. Mahwah, NJ: Lawrence Erlbaum; 2007. p. 91-116.

7. Clutterbuck D. An international perspective on mentoring. In: Ragins BR, Kram KE, editors. The handbook of mentoring at work: theory, research, and practice. Thousand Oaks, CA: Sage; 2007. p. 633-56.

8. Janssen S, van Vuuren M, de Jong MDT. Motives to mentor: Self-focused, protege-focused, relationship-focused, organization-focused, and unfocused motives. J Vocat Behav. 2014;85:266-75.

9. Allen TD, Poteet ML, Russel JEA, Dobbins GH. A field study of factors related to supervisors willingness to mentor others. J Vocat Behav. 1997;50:1-22.

10. Greenhaus JH, Powel GN. When work and family are allies: A theory of work-family enrichment. Acad Manage Rev. 2006;31:72-92.

11. Mezias JM, Scandura TA. A needs-driven approach to expatriate adjustment and career development: a multiple mentoring perspective. J Int Bus Stud. 2005;36:519-38.

12. Eby LT, Allen TD, Hoffman BJ, Baranik LE, Sauer JB, Baldwin S, et al. An interdisciplinary metaanalysis of the potential antecedents, correlates, and consequences of protégé perceptions of mentoring. Psychol Bull. 2013;139:441-76.

13. Kram KE, Ragins BR. The landscape of mentoring in the 21st century. In: Ragins BR, Kram KE, editors. The handbook of mentoring at work: theory, research, and practice. Thousand Oaks, CA: Sage; 2007. p. 659-92.

14. Ragins BR, Scandura TA. Burden or blessing? Expected costs and benefits of being a mentor. J Organ Behav. 1999;20:493-509.

15. Sambunjak D, Straus SE, Marusic A. A systematic review of qualitative research on meaning and characteristics of mentoring in academic medicine. J Gen Intern Med. 2010;25:72-8.

16. Freeman R. Towards effective mentoring in general practice. Br J Gen Pract. 1997;47:457-60.

17. Davis OC, Nakamura J. A proposed model for an optimal mentoring environment for medical residents: A literature review. Acad Med. 2010;85:1060-6.

18. DuBois DL, Karcher MJ, editors. Handbook of youth mentoring. Thousand Oaks, CA: Sage; 2005.
19. Megginson D, Clutterbuck D. Techniques for coaching and mentoring. Oxford: Elsevier; 2005.

20. Sambunjak D, Marusic A. Mentoring - what's in a name? JAMA. 2009;302:2591-2.

21. Boudreau JD, Macdonald ME, Steinert Y. Affirming professional identities through an apprenticeship: insights from a four-year longitudinal case study. Acad Med. 2014;89:1038-45.

22. Pribic S, Gmajnic R. How to improve teaching in family medicine. Acta Med Acad. 2012;41:75-9.

23. Soler JK, Yaman H, Esteva M, Dobbs F, Asenova RS, Katic M, et al. Burnout in European family doctors: the EGPRN study. Fam Pract. 2008;25: 245-65.

24. Polasek O, Petrovecki M, Primorac D, Petrovecki M. Fellowship outcomes and factors associated with scientific successfulness of junior researchers in Croatia. Drustvena istrazivanja. 2007;16:1127-50.

25. Petrovecki M, Smiljanic L, Troselj M, Polasek O. Employment outcomes among junior researchers in medicine in Croatia. Croat Med J. 2008;49:91-7.

26. Buddeberg-Fischer B, Herta KD. Formal mentoring programmes for medical students and doctors - a review of the Medline literature. Med Teach. 2006;28:248-57.

27. Yamada K, Slanetz PJ, Boiselle PM. Perceived benefits of a radiology resident mentoring program: comparison of residents with self-selected vs assigned mentors. Can Assoc Radiol J. 2014;65:186-91.

28. Serwint JR, Cellini MM, Spector ND, Gusic ME. The value of speed mentoring in a pediatric academic organization. Acad Pediatr. 2014;14:33540.

29. Hauer KE, Teherani A, Dechet A, Aagaard EM. Medical students' perceptions of mentoring: a focus-group analysis. Med Teach. 2005;27:732-34.

30. Pinilla S, Pander T, von der Borch P, Fischer MR, Dimitriadis K. 5 years of experience with a largescale mentoring program for medical students. GMS Z Med Ausbild. 2015;32:Doc5.

31. Polasek O, Kolcic I, Buneta Z, Cikes N, Pecina M. Scientific production of research fellows at the Zagreb University School of Medicine, Croatia. Croat Med J. 2006;47:776-82.

32. Anderson WA, Banerjee U, Drennan CL, Elgin SCR, Epstein IR, Handelsman J, et al. Changing the culture of science education at research universities. Science. 2011;331:152-3.

33. Cho CS, Ramanan RA, Feldman MD. Defining the ideal qualities of mentorship: a qualitative analysis of the characteristics of outstanding mentors. Am J Med. 2011;124:453-8.

34. Dougherty TW, Dreher GF. Mentoring and career outcomes. In: Ragins BR, Kram KE, editors. The 
handbook of mentoring at work: theory, research, and practice. Thousand Oaks, CA: Sage; 2007. p. 51-94.

35. Chao GT, Moon H. The cultural mosaic: A metatheory for understanding the complexity of culture. J Appl Psychol. 2005;90:1128-40.

36. Williams LL, Levine JB, Malhotra S, Holtzheimer P. The good-enough mentoring relationship. Acad Psychiatry. 2004;28:111-5.

37. Gentry WA, Weber TJ, Sadri G. Examining careerrelated mentoring and managerial performance across cultures: A multilevel analysis. J Vocat Behav. 2008;72:241-53.

38. Wang P, Zhao X, Foo MD. Sometimes it's better to leave me alone: the moderating role of culture on the relationship between leaders' mentoring and subordinate motivation. In: Proceedings of the Academy of International Business Southeast Asia Regional Conference, pp. 1-34. From: Academy of International Business Southeast Asia Regional Conference, 5-7 December 2013, Bali, Indonesia.

39. Straus SE, Chatur F, Taylor M. Issues in the mentor-mentee relationship in academic medicine: a qualitative study. Acad Med. 2009;84:135-9.

40. Licht AN, Goldschmidt C, Schwartz SH. Culture rules: The foundations of the rule of law and other norms of governance. J Comp Econ. 2007;35:659-88.

41. Savickas ML. Foreword: The maturation of mentoring research. In: Allen TD, Eby LT, editors. The Blackwell handbook of mentoring: a multiple per- spectives approach. Malden, MA: Blackwell Publishing; 2007.

42. Higgins MC, Kram KE. Reconceptualizing mentoring at work: a developmental network perspective. Acad Manage Rev. 2001;26:264-88.

43. DeCastro R, Sambuco D, Ubel PA, Stewart A, Jagsi R. Mentor networks in academic medicine: moving beyond a dyadic conception of mentoring for junior faculty researchers. Acad Med. 2013;88:488-96.

44. Harris JE, González López-Valcárcel B, Ortun V, Barber P. Specialty choice in times of economic crisis: a cross-sectional survey of Spanish medical students. BMJ Open. 2013;3:e002051.

45. Papadimos TJ, Murray SJ. Foucault's "fearless speech" and the transformation of mentoring of medical students. Philos Ethics Humanit Med. 2008;3:12.

46. Ackers L, Gill B. Moving people and knowledge: Scientific mobility in an enlarging European Union. Chelthenham: Edward Elgar; 2008.

47. Beech BM, Calles-Escandon J, Hairston KG, Langdon SE, Latham-Sadler BA, Bell RA. Mentoring programs for underrepresented minority faculty in academic medical centers: a systematic review of the literature. Acad Med. 2013;88:541-9.

48. Rodriguez JE, Campbell KM, Fogarty JP, Williams RL. Underrepresented minority faculty in academic medicine: a systematic review of URM faculty development. Fam Med. 2014;46:100-4. 